\title{
Aspiration Pneumonitis
}

National Cancer Institute

\section{Source}

National Cancer Institute. Aspiration Pneumonitis. NCI Thesaurus. Code C34932.

Inflammation of the lungs due to the inhalation of solid or liquid material. 